\title{
Primary production sensitivity to phytoplankton light attenuation parameter increases with transient forcing
}

\author{
Karin F. Kvale ${ }^{1}$ and Katrin J. Meissner ${ }^{2}$ \\ ${ }^{1}$ GEOMAR Helmholtz-Zentrum für Ozeanforschung Kiel, Düsternbrooker Weg 20, 24105 Kiel, Germany \\ ${ }^{2}$ Climate Change Research Centre and ARC Centre of Excellence for Climate System Science, University of New South \\ Wales Sydney, Sydney, New South Wales 2052, Australia \\ Correspondence to: Karin F. Kvale (kkvale@geomar.de)
}

Received: 31 March 2017 - Discussion started: 13 April 2017

Revised: 3 September 2017 - Accepted: 21 September 2017 - Published: 25 October 2017

\begin{abstract}
Treatment of the underwater light field in ocean biogeochemical models has been attracting increasing interest, with some models moving towards more complex parameterisations. We conduct a simple sensitivity study of a typical, highly simplified parameterisation. In our study, we vary the phytoplankton light attenuation parameter over a range constrained by data during both pre-industrial equilibrated and future climate scenario RCP8.5. In equilibrium, lower light attenuation parameters (weaker self-shading) shift net primary production (NPP) towards the high latitudes, while higher values of light attenuation (stronger shelf-shading) shift NPP towards the low latitudes. Climate forcing magnifies this relationship through changes in the distribution of nutrients both within and between ocean regions. Where and how NPP responds to climate forcing can determine the magnitude and sign of global NPP trends in this high $\mathrm{CO}_{2}$ future scenario. Ocean oxygen is particularly sensitive to parameter choice. Under higher $\mathrm{CO}_{2}$ concentrations, two simulations establish a strong biogeochemical feedback between the Southern Ocean and low-latitude Pacific that highlights the potential for regional teleconnection. Our simulations serve as a reminder that shifts in fundamental properties (e.g. light attenuation by phytoplankton) over deep time have the potential to alter global biogeochemistry.
\end{abstract}

\section{Introduction}

Treatment of marine light availability for photosynthesis in biogeochemical compartments of ocean general circulation models (OGCMs) has largely avoided careful scrutiny un- til recently (e.g. Dutkiewicz et al., 2015; Kim et al., 2015; Gregg and Rousseaux, 2016). These models typically use simplified, empirically based parameterisations of phytoplankton growth rates related to photosynthetically available radiation (PAR) based on the state of the science in the 1970s and 1980s. The OGCM in the University of Victoria Earth System Climate Model (UVic ESCM; Weaver et al., 2001; Eby et al., 2009) is one example. In it, the irradiance $(I)$ at each depth level is calculated as

$$
\begin{aligned}
I= & I_{z=0} \operatorname{PARexp}\left(-k_{\mathrm{w}} \tilde{z}-k_{\mathrm{c}} \int_{0}^{\tilde{z}}(P+\operatorname{Diaz}) \mathrm{d} z\right) \\
& \cdot\left[1+a_{\mathrm{i}}\left(\exp \left(-k_{\mathrm{i}}\left(h_{\mathrm{i}}+h_{\mathrm{s}}\right)\right)-1\right)\right]
\end{aligned}
$$

(Schmittner et al., 2005; Kirk, 1983), where PAR stands for photosynthetically available radiation, $k_{\mathrm{w}}, k_{\mathrm{c}}$, and $k_{\mathrm{i}}$ are light attenuation coefficients for water, phytoplankton (diazotrophs and general phytoplankton), and ice, $\widetilde{z}$ is the effective vertical coordinate, $a_{\mathrm{i}}$ is the fractional sea ice cover, and $h_{\mathrm{i}}$ and $h_{\mathrm{s}}$ are calculated sea ice and snow cover thicknesses. Phytoplankton concentration ( $P$ and Diaz) is expressed in a base unit of mmol $\mathrm{N} \mathrm{m}^{-3}$. Light attenuation coefficients $k_{\mathrm{W}}$ and $k_{\mathrm{i}}$ have the unit of $\mathrm{m}^{-1}$, but light attenuation by phytoplankton is dependent on phytoplankton concentration (Kirk, 1975) and $k_{\mathrm{c}}$ is expressed in units of $\left(\mathrm{m} \mathrm{mmol} \mathrm{N} \mathrm{m}^{-3}\right)^{-1}$. However, $k_{\mathrm{c}}$ cannot be considered to represent the light attenuation of phytoplankton only, but also represents the attenuation of constituents that are assumed to co-vary with phytoplankton (i.e. particulate and dissolved inorganic and organic materials). Light attenuation coefficients are classified as apparent optical properties (AOP) because they rep- 
resent the combined effect of the inherent optical properties (IOP) of the medium (e.g. seawater or phytoplankton cells) and the optical properties of the radiation field (see Kirk, 1983; Falkowski and Woodhead, 1992, and associated references). Early tests of $k_{\mathrm{c}}$ (e.g. Fasham et al., 1990) demonstrated low model biomass sensitivity to parameter value choice, and this has been the prevailing wisdom of biogeochemical modellers for over 20 years. Estimates of $k_{\mathrm{c}}$ vary widely: for example, $0.014 \mathrm{~m}^{2}(\mathrm{mg} \mathrm{Chl} a)^{-1}$ (generally applicable, Lorenzen, 1972), $0.041 \mathrm{~m}^{2}(\mathrm{mg} \mathrm{Chl} a)^{-1}$ (Southern Ocean, Bracher and Tilzer, 2001), or a range from 0.006 to $0.015 \mathrm{~m}^{2}(\mathrm{mg} \mathrm{Chl} a)^{-1}$ assuming all phytoplankton represent mixes of specific species of dinoflagellates, calcifiers, or diatoms (Falkowski et al., 1985). Even the assumption that $k_{\mathrm{c}}$ varies predictably with chlorophyll concentration can be considered highly simplistic because the co-varying constituents might cause this ratio to fluctuate (Siegel et al., 2005). In practice, any value assigned to $k_{\mathrm{c}}$ is going to be highly model-dependent (e.g. $0.058 \mathrm{~m}^{2}(\mathrm{mg} \mathrm{Chl} a)^{-1}$ in Wang et al., 2008) because of the wide range of observational estimates and the necessary conversion from chlorophyll to model nutrient units, which requires some assumptions that depend on model structure.

While it was recognized early on that a rigorous description of the spectral composition of the underwater light field must separate effects of IOP from the radiation field, early measurements emphasized AOP because of technological limitations as well as for a lack of data resolving the IOP of seawater constituents (Kirk, 1983). Research into the IOP of these constituents has since benefited from continuously improving analytical tools, including satellite remote sensing, whose algorithms depend on their resolution (Sathyendranath and Platt, 2007). Phytoplankton IOP are speciesspecific (e.g. Stramski et al., 2001). Of the major seawater constituents, detrital particles contribute the most to light scattering and attenuation, and picoplankton are the primary phytoplankton light absorbers (Stramski et al., 2001; Fujii et al., 2007), though their contribution to absorption is possibly exceeded by coloured dissolved organic matter (CDOM) (Siegel et al., 2005; Fujii et al., 2007).

Recent work has highlighted what we potentially miss in our OGCMs, and hence our earth system models (ESMs) as well, by neglecting explicit radiative transfer and IOP. Decomposing the calculation of underwater irradiance into IOP, resolving a variable number of radiative wavebands, and then testing three parameterisations of light limitation of phytoplankton growth in a one-dimensional ecosystem model comparable to observational data show that a model resolving multiple wavebands and a spectral sensitivity in photosynthesis outperformed a simple parameterisation similar to Eq. (1) (Kettle and Merchant, 2008). Choice in parameterisation of spectral resolution can contribute percentage errors of up to $200 \%$ (Kettle and Merchant, 2008). Not including a radiative transfer model in an OGCM can reduce global nitrate by $33 \%$ and chlorophyll by $24 \%$, and bring about large changes in phytoplankton biogeography, even when there is no change in total irradiance (Gregg and Rousseaux, 2016). Dutkiewicz et al. (2015) offer the most complicated model analysis, and demonstrate that explicitly resolving radiative transfer and the IOP of phytoplankton types, detritus, and CDOM in a three-dimensional ocean model can improve model performance against observational data. Their sensitivity analysis demonstrates complex feedbacks between light, phytoplankton attributes, and biogeochemistry (Dutkiewicz et al., 2015).

Explicit radiative transfer and fully resolved IOP add computational expense to already expensive ESMs. Since empirically based AOP parameterisations are still widely used and economical, it is useful to test their limitations and sensitivities. Including light attenuation by phytoplankton in an OGCM amplifies the seasonal cycle of temperature, mixed layer depth, and ice cover by about $10 \%$ over neglecting it altogether (Manizza et al., 2005). Gnanadesikan and Anderson (2009) find the inclusion of light attenuation by chlorophyll in an OGCM alters physical water mass characteristics, including a decrease in subsurface temperatures by over $2{ }^{\circ} \mathrm{C}$ at the low latitudes. Kim et al. (2015) explore the biogeochemical consequences of differentiating light attenuation by CDOM and detrital particles from that of chlorophyll in an ESM and find these components increased surface phytoplankton biomass by reducing levels of light at depth, which reduced deeper production and made more nutrients available at the surface. Two model simulations with and without CDOM and detrital particle light attenuation differ by $9 \%$ in the global average biomass and $7 \%$ in the global carbon export flux at $200 \mathrm{~m}$ depth (Kim et al., 2015). These are modest changes with respect to other production and export parameters (e.g. Kwon et al., 2009 found a $5 \mathrm{GtC} \mathrm{yr}^{-1}$, or $50 \%$, increase in global carbon export by raising the export transfer efficiency exponent by 0.4 ), though regional sensitivities are stronger (Kim et al., 2015).

All of the studies mentioned above make their comparisons using models to which pre-industrial forcings are applied. Dutkiewicz et al. (2015) highlighted the potential for complex feedbacks arising due to model treatment of light and optical properties; therefore, it stands to reason that such feedbacks may be compounded under climate change. A recent bug fix in the implementation of Eq. (1) in the UVic ESCM prompted a hasty equilibrated model re-evaluation, which then led to our more thorough assessment including climate change. Future implementation of a more complex radiative transfer and phytoplankton IOP model may be justified based on the conclusions of the authors above (e.g. Dutkiewicz et al., 2015); however, the UVic ESCM (and other models of similar structure) is widely used in its current form and it is therefore worthwhile assessing and reporting on its current sensitivities. The aim of our study is to assess the sensitivity of modelled net primary production to phytoplankton light attenuation parameter value in an ESM using pre-industrial equilibrated, historical, and projected climate 
forcing. The drivers of net primary production are of scientific interest as they may respond to anthropogenic climate change (e.g. Kvale et al., 2015; Laufkötter et al., 2015). To our knowledge, such a simple assessment has not appeared in the peer-reviewed domain despite there being a wide range of phytoplankton light attenuation parameter values currently in use (described in more detail below) and a demonstrated sensitivity of primary production, export, and nutrients in OGCMs and ESMs to how the underwater light field is modelled (described above).

\section{Methods}

The University of Victoria Earth System Climate Model (UVic ESCM, Weaver et al., 2001; Eby et al., 2009) version 2.9 is a coarse-resolution $\left(1.8^{\circ} \times 3.6^{\circ} \times 19\right.$ ocean depth layers) ocean-atmosphere-biosphere-cryosphere-geosphere model. The biogeochemical component (Schmittner et al., 2005, 2008; Keller et al., 2012) is a nutrients-phytoplanktonzooplankton-detritus (NPZD) model with two phytoplankton types (general phytoplankton and diazotrophs), one zooplankton type, and chemical tracers nitrate, phosphate, dissolved inorganic carbon, alkalinity, and oxygen. Iron limitation is accounted for using a seasonally variable mask of dissolved iron concentrations in the upper three ocean layers (Keller et al., 2012). The biogeochemistry is comprehensively assessed in Keller et al. (2012); however, the model has since been updated with several bug fixes and minor adjustments. Only one of the bug fixes is relevant to our study. In previous published versions of the model, the depth was incorrectly calculated for the light availability equation in a way that resulted in too much light in the first ocean depth level. This calculation is corrected here.

Our study examines model biogeochemical sensitivity to a spread of $k_{\mathrm{c}}$ values at both equilibrium in a pre-industrial climate (atmospheric $\mathrm{CO}_{2}$ concentration of $283.8 \mathrm{ppm}$ ) and a future projection. We use historical atmospheric $\mathrm{CO}_{2}$ concentrations, agricultural land cover, volcanic radiative forcing, sulfate aerosol, and CFC concentrations to force the model, as well as changes in land ice and solar forcing from years 1800 to 2005 following Machida et al. (1995), Battle et al. (1996), Etheridge et al. (1996), Etheridge et al. (1998), Flückiger et al. (1999), Flückiger et al. (2004), Ferretti et al. (2005), and Meure et al. (2006). From years 2005 to 2300 the simulations were forced using increasing $\mathrm{CO}_{2}$ and non$\mathrm{CO}_{2}$ greenhouse gas concentrations, projected changes to the fraction of the land surface devoted to agricultural uses (calculated to year 2100 by Hurtt et al., 2011, and then held constant after), and changes in the direct effect of sulfate aerosols following "business-as-usual" RCP scenario 8.5 (RCP8.5, Riahi et al., 2007; Meinshausen et al., 2011). Solar insolation at the top of the atmosphere, wind stress, and wind fields varied seasonally (Kalnay et al., 1996), and the wind fields were geostrophically adjusted to air temperature anomalies
(Weaver et al., 2001). The sediment and weathering models (Meissner et al., 2012) were not used. Model equilibration was achieved by integrating over 10000 years prior to application of climate forcing.

The simplistic nature of Eq. 1 makes our study highly idealized. Parameter $k_{\mathrm{w}}$ represents light attenuation of water and is fairly well constrained to about $0.04 \mathrm{~m}^{-1}$ (Lorenzen, 1972), which is its assigned value in our model. The light attenuation of an ice parameter is not examined here: any primary production sensitivity to variation in $k_{\mathrm{i}}$ is likely to have effects relegated to the high latitudes. Light attenuation by phytoplankton also implicitly accounts for attenuation of light by co-varying factors, with the current default model value applied to both diazotrophs and the single general phytoplankton type (Eq. 1). The Schmittner et al. (2008) $k_{\mathrm{c}}$ value of $0.03\left(\mathrm{~m} \mathrm{mmol} \mathrm{N} \mathrm{m}^{-3}\right)^{-1}$ was increased in Keller et al. (2012) to $0.047\left(\mathrm{~m} \mathrm{mmol} \mathrm{N} \mathrm{m}^{-3}\right)^{-1}$. Light attenuation parameters are measured based on chlorophyll (commonly chlorophyll $a$ ) concentration, but the model uses nitrogen units, necessitating the application of a conversion factor also implicit in $k_{\mathrm{c}}$. Conversion of the range of $k_{\mathrm{c}}$ values given above $\left(0.006\right.$ to $\left.0.041 \mathrm{~m}^{2}(\mathrm{mg} \mathrm{Chl} a)^{-1}\right)$ to carbon and then nitrogen units using the maximum Chl $a$ to carbon ratio for non-diatom phytoplankton in Table 4 of Dutkiewicz et al. (2015) and the Redfield $\mathrm{C}: \mathrm{N}$ ratio used in our model (6.625) yields a range of 0.008 to $0.054\left(\mathrm{~m} \mathrm{mmol} \mathrm{N} \mathrm{m}^{-3}\right)^{-1}$ in the observationally based literature (though higher values in models exist - Evans and Parslow, 1985, used a value of $\left.0.12\left(\mathrm{~m} \mathrm{mmol} \mathrm{N} \mathrm{m}^{-3}\right)^{-1}\right)$. For our test, we employ eight separate simulations using $k_{\mathrm{c}}=0.01,0.02,0.03,0.04,0.05$, $0.06,0.07$, and $0.08\left(\mathrm{~m} \mathrm{mmol} \mathrm{N} \mathrm{m}^{-3}\right)^{-1}$. Increasing the light attenuation parameter value increases the self-shading effect of the phytoplankton biomass, reducing the amount of light available for photosynthesis. In the following analysis they will be referred to as "K1-8", as we assess the impact of parameter choice on model net primary production, and carbon and nutrient distributions in a model equilibrated to preindustrial climate conditions and then forced with historical and projected greenhouse gas concentrations. Gridded observations from the World Ocean Atlas climatology (Garcia et al., 2010a, b) (phosphate, nitrate, and oxygen) and GLODAP (Key et al., 2004) (DIC and alkalinity) are compared to the pre-industrial model.

\section{Results}

\subsection{Pre-industrial equilibrium simulations}

Patterns of equilibrated net primary production (NPP) in the UVic ESCM are sensitive to $k_{\mathrm{c}}$ within the tested range. Depth-integrated zonally and annually averaged NPP, and horizontally and annually averaged NPP, are shown in Fig. 1. The simulation spread is smallest between 20 and $40^{\circ}$, where phytoplankton biomass is low. The tropics and regions 

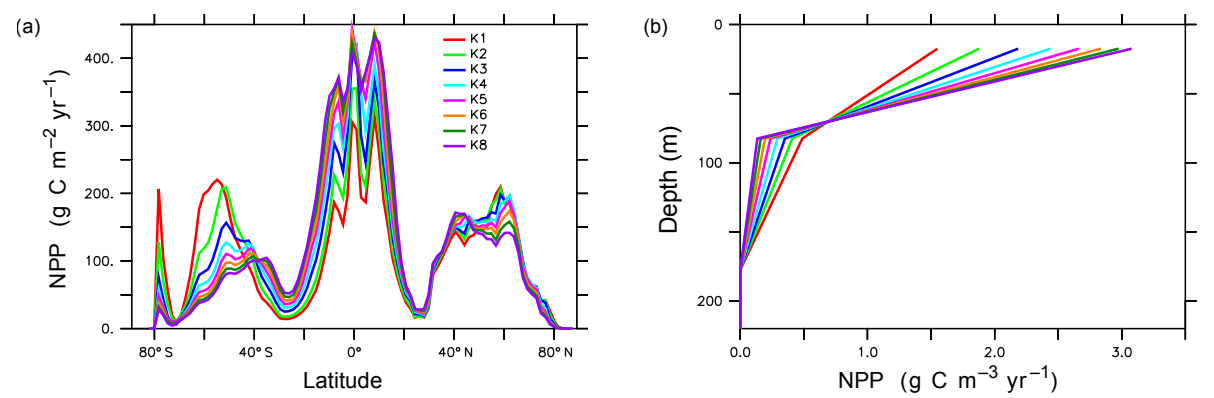

Figure 1. Annually and zonally averaged pre-industrial, depth-integrated NPP (a), and annually and globally averaged NPP with depth (b).
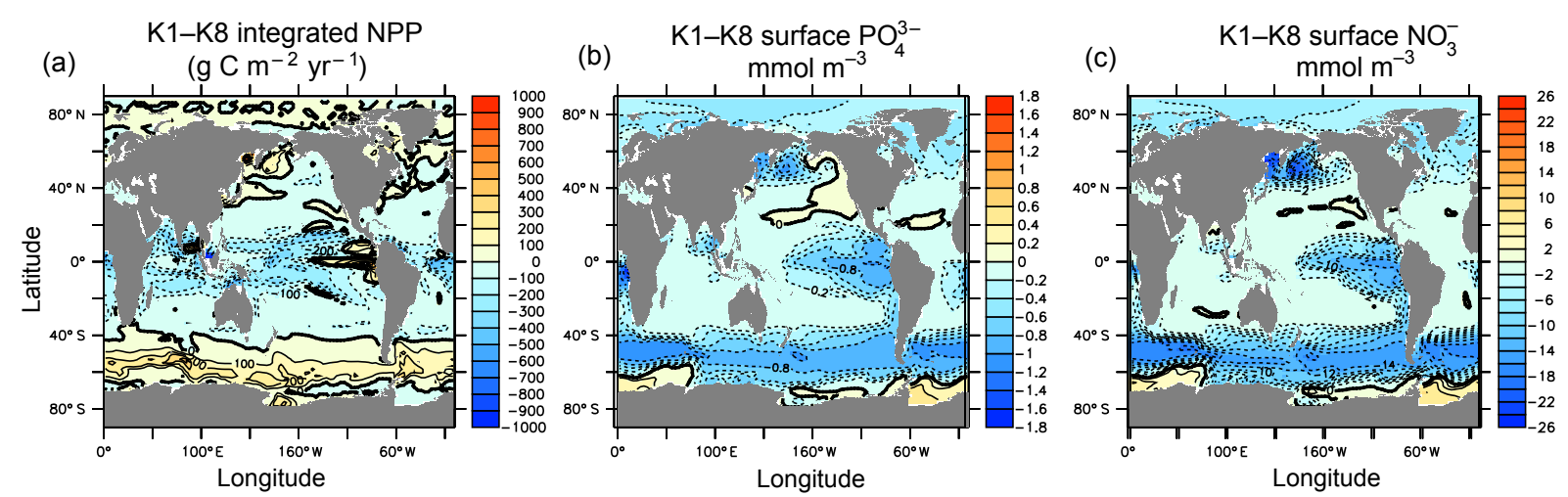

Figure 2. Annually averaged pre-industrial differences between K1 and K8 for depth-integrated NPP (a), surface phosphate (b), and surface nitrate (c).

between 40 and $75^{\circ}$, particularly in the Southern Ocean, show the largest differences in NPP with varying $k_{\mathrm{c}}$. In the tropics, the differences in simulated zonal mean NPP between end members $\mathrm{K} 1$ and $\mathrm{K} 8$ exceed $200 \mathrm{~g} \mathrm{C} \mathrm{m}^{-3} \mathrm{yr}^{-1}$, while regional differences in depth-integrated NPP exceed $200 \mathrm{~g} \mathrm{C} \mathrm{m}^{-3} \mathrm{yr}^{-1}$ over large parts of the Southern Ocean and tropics (Fig. 2). In the Southern Ocean, K1 zonally averaged primary production rates can exceed those of $\mathrm{K} 8$ by more than a factor of 3 because phytoplankton in $\mathrm{K} 1$ do not selfshade as strongly during the austral summer, thereby allowing for a stronger seasonal cycle. South of this region (around $60^{\circ} \mathrm{S}$ ) UVic ESCM primary production transitions to being light-limited from being nutrient-limited to the north (annually averaged limitation regimes are shown in Fig. 3), and so reducing the self-shading increases primary production in the light-limited regime. The transition zone between light and nutrient limitation is well mixed, and lateral advection of regenerated nutrients from the light-limited regime boosts NPP in the nutrient-limited regime in low- $k_{\mathrm{c}}$ value simulations. In the more stratified (and nutrient-limited) tropics, the effect is opposite in that K8 yields zonally averaged NPP of up to double $\mathrm{K} 1$ because stronger self-shading inhibits deeper photosynthesis (see the globally averaged NPP depth profile plot in Fig. 1, which is dominated by the low-latitude response), making more regenerated nutrients available at the surface (Figs. 2 and 4, and similar to the effect of light attenuation by CDOM described previously by Kim et al., 2015). Higher nutrient concentrations at the tropical surface in K8 cause a net increase in depth-integrated primary production because of the temperature dependency of primary production and respiration in the model (the warmer surface increases the production and remineralisation rates, resulting in higher NPP). Simulation differences in the tropical eastern Pacific upwelling region arise from processes similar to those described in the Southern Ocean. While the eastern Pacific upwelling zone is nutrient-limited in our model (like the rest of the tropics, Fig. 3), a weak near-surface temperature gradient reduces primary production in the surface layer. Higher light availability in K1 therefore allows for deeper utilization of upwelled nutrients, resulting in higher depth-integrated NPP in $\mathrm{K} 1$ compared to K8. Three distinct regional responses to $k_{\mathrm{c}}$ parameter value choice are therefore apparent. In regions that are light-limited, reducing the light attenuation parameter results in higher NPP (Southern Ocean and Arctic). In regions that are nutrient-limited, reducing the light attenuation parameter results in lower NPP when combined with a strong vertical temperature gradient near the surface (tropics and subtropical gyres). In regions that are nutrient-limited and are characterized by a weak vertical temperature gradient near the surface, reducing the light attenuation parameter results in higher NPP (eastern Pacific, western boundary currents). The northern hemisphere midlatitudes do not show 

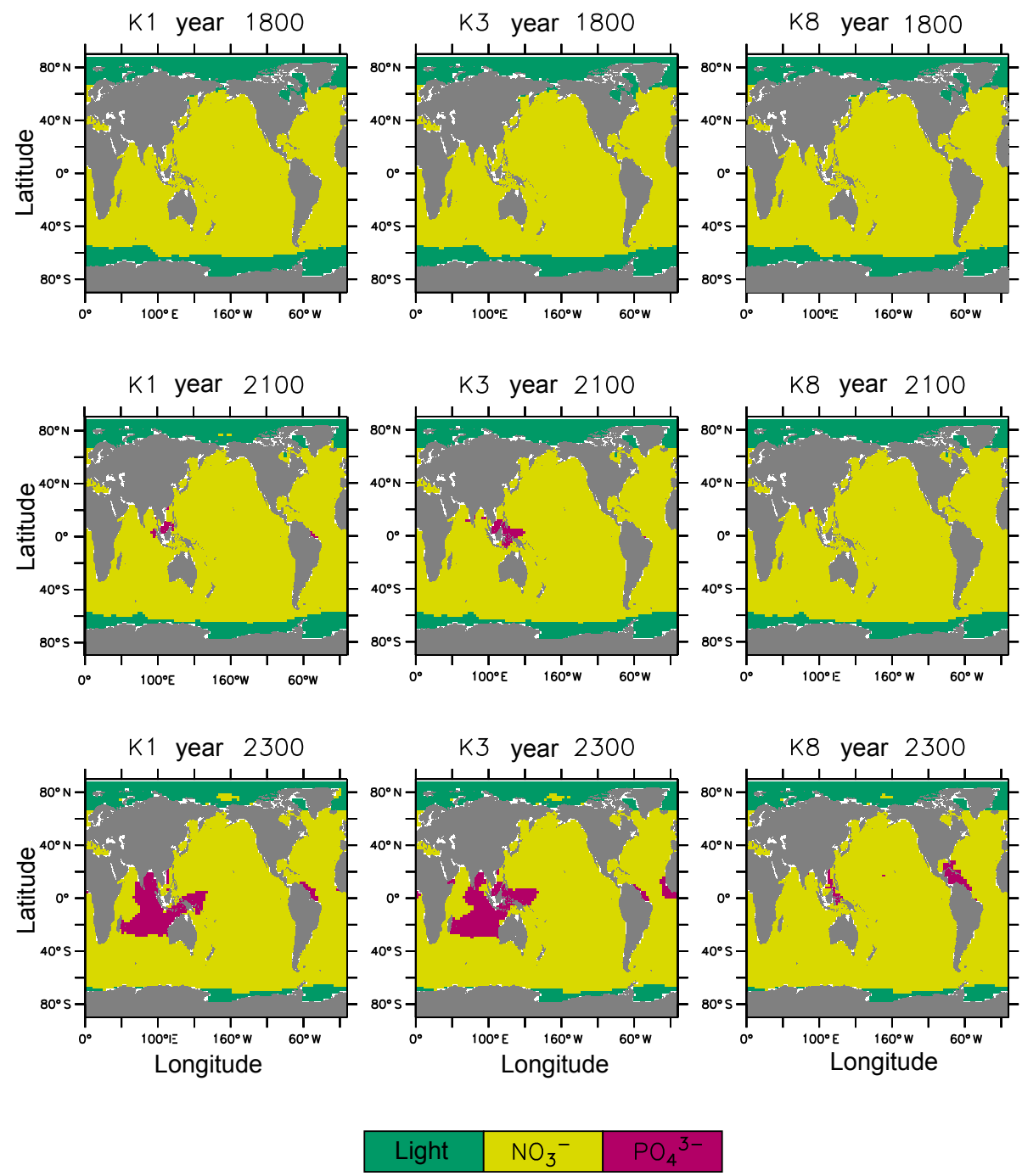

Figure 3. K1, K3, and K8 light and nutrient limitation regions for years 1800, 2100, and 2300.

as clear a zonally averaged NPP- $k_{\mathrm{c}}$ relationship, as can be seen in the Southern Hemisphere and the tropics, because the western boundary currents and oligotrophic regions oppose each other in the North Atlantic and North Pacific.

Carbon and nutrient distributions in the UVic ESCM are also sensitive to $k_{\mathrm{c}}$ because parameter choice affects the efficiency of the biological pump (Fig. 1), leading to a redistribution of nutrients (Fig. 4). Low-value $k_{\mathrm{c}}$ simulations experience a greater proportion of global NPP at the high latitudes (regions with higher sequestration efficiency; DeVries et al., 2012), and increasing the $k_{\mathrm{c}}$ value shifts NPP towards the tropics (a region of lower sequestration efficiency; DeVries et al., 2012). As a consequence, more nutrients and carbon end up in the abyssal Pacific Ocean in low-value $k_{\mathrm{c}}$ simulations than in higher-value ones. Increased storage of nutrients in this deep ocean basin reduces the inventory available for subduction in the northern Atlantic (e.g. Kwon and
Primeau, 2006; Kwon et al., 2009; Kriest et al., 2012), where water column concentrations of nitrate and phosphate decline (Fig. 4). Increasing $k_{\mathrm{c}}$ values reduces average surface alkalinity (Fig. 4) by about $50 \mu \mathrm{mol} \mathrm{kg}{ }^{-1}$ globally, a response to increasing low-latitude NPP (including a stronger carbonate pump) with higher $k_{\mathrm{c}}$ values. In low-value $k_{\mathrm{c}}$ simulations, alkalinity is higher in the Atlantic as a result of the decline of the Atlantic biological pump. Deep ocean alkalinity is less sensitive to $k_{\mathrm{c}}$ value, though the average deep Pacific also shows a range of about $50 \mu \mathrm{mol} \mathrm{kg}-1$ and the Southern Ocean varies by about $25 \mu \mathrm{mol} \mathrm{kg}{ }^{-1}$. Deep ocean DIC, however, is more sensitive to choice of $k_{\mathrm{c}}$ value (Fig. 4). K4-K8 DIC ranges in basin averages less than $30 \mu \mathrm{mol} \mathrm{kg}{ }^{-1}$, but sensitivity increases at lower $k_{\mathrm{c}}$ values. K1 deep DIC values are about $40 \mu \mathrm{mol} \mathrm{kg}{ }^{-1}$ higher in the global average, Pacific, and Southern Ocean basins than in K2. These higher deep DIC values are a consequence of higher NPP at the high latitudes 

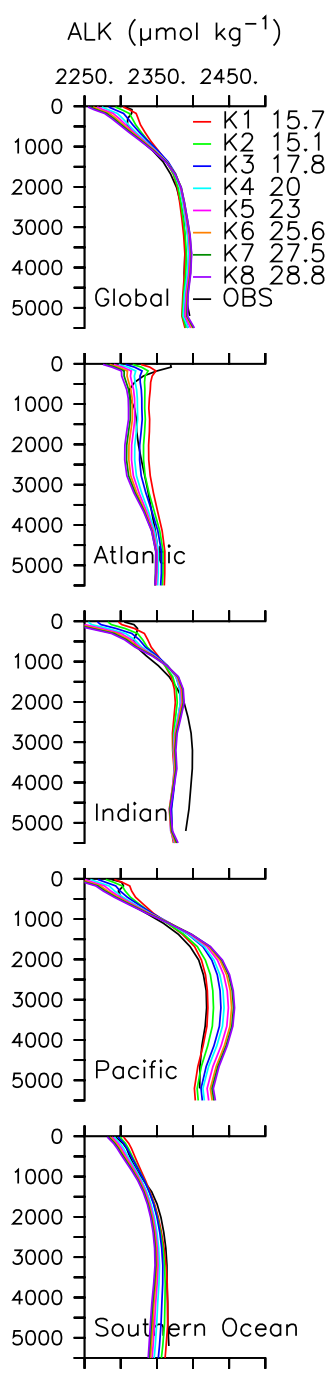
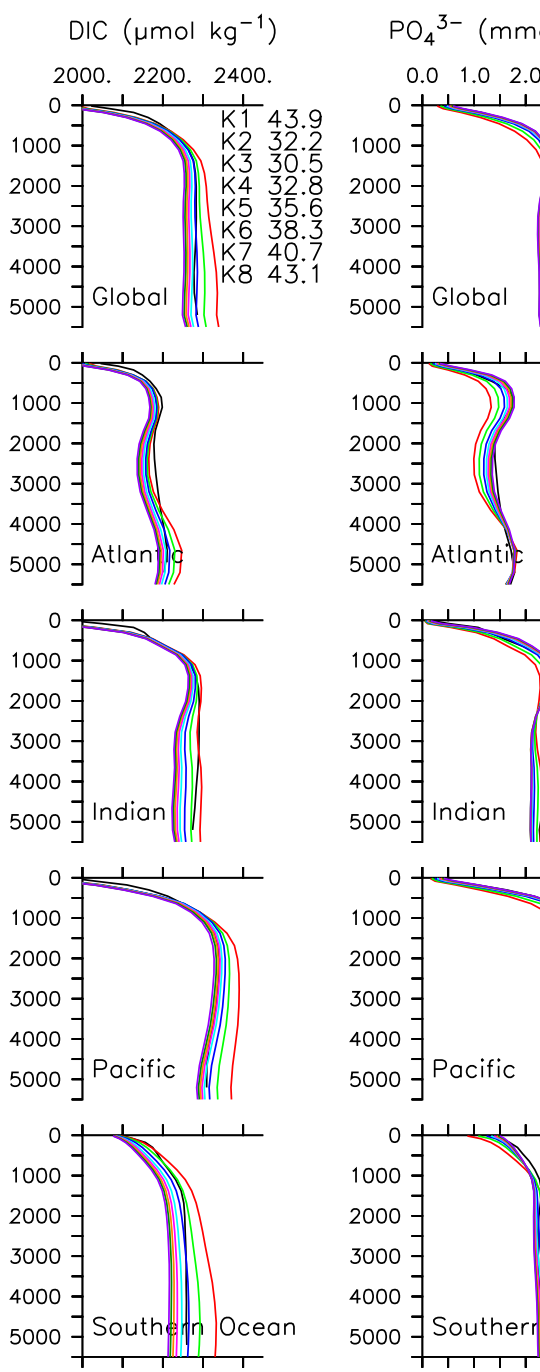
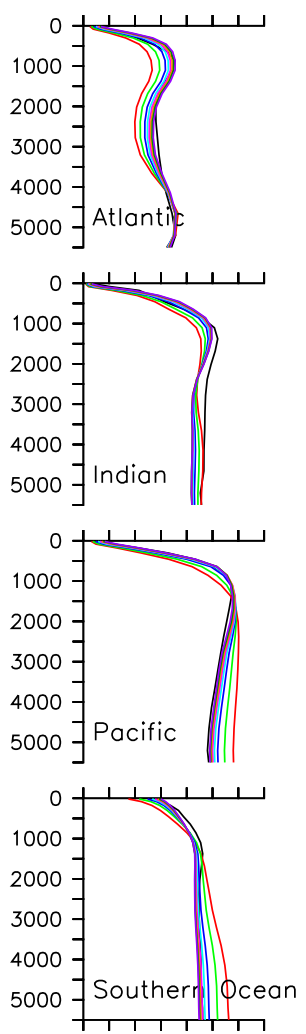

$\mathrm{NO}_{3}^{-}\left(\mathrm{mmol} \mathrm{m}{ }^{-3}\right)$

0. $10 \cdot 20 \cdot 30 \cdot 40 \cdot 50$.
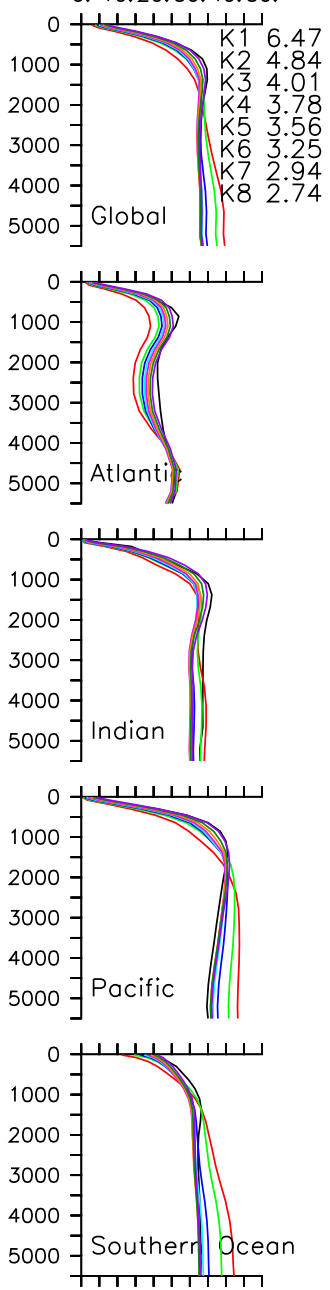
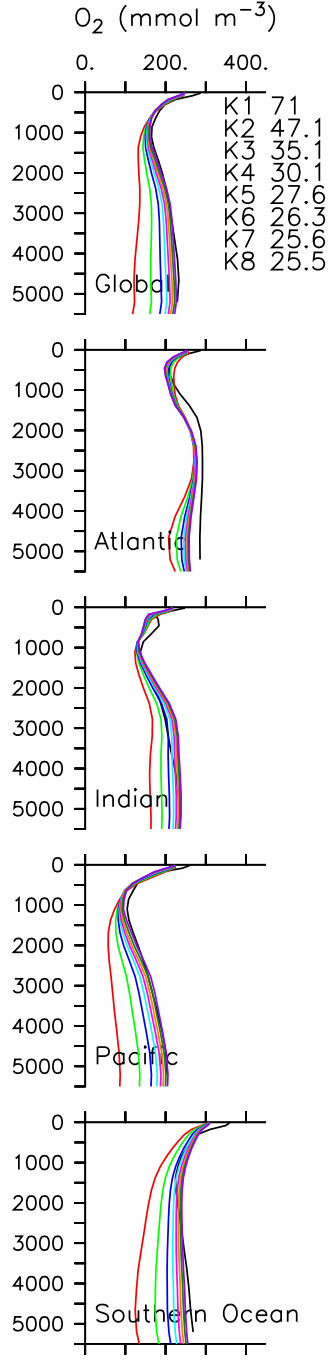

Figure 4. Annual mean pre-industrial biogeochemical tracer profiles averaged by ocean basin for all simulations compared to gridded observations. Global root mean square error is provided for each simulation.

owing to a weaker self-shading effect, which increases carbon and nutrient export to the deep ocean. Phosphate and nitrate basin-averaged profiles show a range of values generally proportional to the range in DIC, with drivers of the differences being the same (lower $k_{\mathrm{c}}$ values yield higher global NPP, lower surface nutrients, and higher deep ocean nutrients, as well as a shift in NPP to higher latitudes, Fig. 4). Likewise, deep ocean oxygen is lower for lower $k_{\mathrm{c}}$ values because there is more deep ocean remineralisation (Fig. 4). The global average deep ocean oxygen concentration has a range of about $100 \mathrm{mmol} \mathrm{m}^{-3}$, which is about half of the average deep ocean content. The Southern Ocean and Pacific show similar oxygen sensitivity.

Which $k_{\mathrm{c}}$ value performs the "best" with respect to biogeochemical observations is not thoroughly quantified here, but generally $\mathrm{K} 4$ and above perform better with respect to deep ocean nutrients and oxygen, $\mathrm{K} 2$ to $\mathrm{K} 5$ do better with respect to global DIC, and $\mathrm{K} 1$ and $\mathrm{K} 2$ outperform the others with respect to global alkalinity (see global RMSE values in Fig. 4). As discussed in Sect. 1, selection of a single model $k_{\mathrm{c}}$ value to represent all ocean biology and co-varying factors is fairly ad hoc, and consequently, the range of values we selected for this sensitivity comparison are as well. Based on Figs. 1 and 4, the two lowest $k_{\mathrm{c}}$ values we selected perform anomalously with respect to the others (higher Southern Ocean NPP, deep ocean DIC, nitrate, and phosphate and much lower deep ocean oxygen). Therefore we will examine two groups of $K$ values in Sect. 3.2, K1-K8 (the full range tested) and $\mathrm{K} 3-\mathrm{K} 8$ (the subset better reproducing modern deep ocean biogeochemistry).

\subsection{RCP 8.5 transient simulations}

Figure 5 plots the increase in atmospheric $\mathrm{CO}_{2}$ concentration from 283.8 to $1962 \mathrm{ppm}$ over the course of the transient inte- 

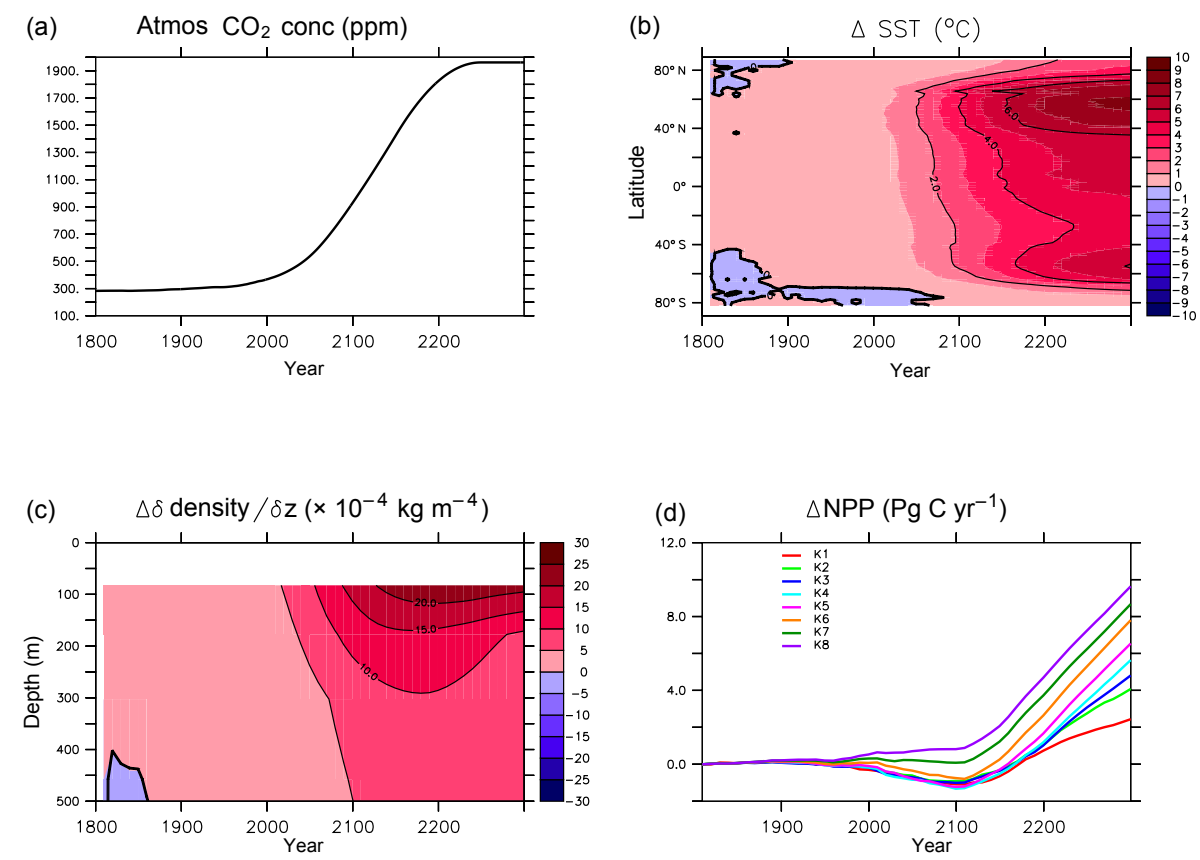

Figure 5. Atmospheric $\mathrm{CO}_{2}$ concentration forcing of all simulations (a). Zonally averaged change in sea surface temperature in all simulations (b). Change in global average density gradient with depth in all simulations (c). Change in globally integrated net primary production in all simulations $(\mathbf{d})$.

gration. The physical response is the same across all simulations and closely follows that described in Kvale et al. (2015). Zonally averaged ocean surface temperatures rise by as much as $10^{\circ} \mathrm{C}$, North Atlantic maximum meridional overturning reduces from 20 to 9 Sverdrups (not shown), and widespread near-surface stratification occurs (Fig. 5). The phytoplankton and zooplankton respond to surface warming by increasing metabolic rates, and microbial fast recycling in the near surface increases (Kvale et al., 2015). Stratification reduces the availability of nutrients in the near surface. The global response in NPP until about the year 2100 depends on the simulation, with K1-K6 showing a decline, and K7 and K8 showing no change and an increase in NPP, respectively. After about year 2100, global NPP in K4-K8 increases linearly, while global NPP increases at a declining rate in K1-K3.

Model spread in global NPP response generally increases with radiative forcing. Change in global NPP differs by $2.5 \mathrm{Pg} \mathrm{C} \mathrm{yr}^{-1}$ by 2100 (more than $100 \%$ of the total change in NPP at 2100 for all simulations) and $k_{\mathrm{c}}$ parameter choice can determine the sign of the change. This applies even when only considering the subset of $k_{\mathrm{c}}$ parameters offering the better fits to pre-industrial nutrient and carbon observations (K3-K8) and excluding K1 and K2. By 2300 this spread has increased to $7 \mathrm{PgC} \mathrm{yr}^{-1}$ across all simulations, and $5 \mathrm{PgC} \mathrm{yr}^{-1}$ between $\mathrm{K} 3$ and $\mathrm{K} 8$. By 2300, the spread between $\mathrm{K} 3$ and $\mathrm{K} 8$ is roughly equal to the all-simulation average change in NPP since 1800, suggesting choice of $k_{\mathrm{c}}$ value can have a significant and increasing effect on global NPP response to climate forcing.
Before the year 2100, physical limitation of nutrients is the dominant driver of changes in global NPP (Kvale et al., 2015). Over this time, choice of $k_{\mathrm{c}}$ parameter value affects the magnitude and direction of how NPP in different regions responds. Increasingly oligotrophic conditions expand the extent of nutrient-limited regions, with phosphate limitation arising in the tropics in lower $k_{\mathrm{c}}$ value simulations (shown for K1 and K3 in Fig. 3). More nutrient limitation results in declining global NPP in the simulations with weaker self-shading (K1-K6). In these simulations, lower starting concentrations of surface nutrients cause the biology in these simulations to be more sensitive to an increase in stratification. Figure 6 (left plot) shows some decline between years 1800 and 2100 in tropical depth-integrated NPP between 10 and $20^{\circ}$ for all simulations, with the declines generally increasing with decreasing $k_{\mathrm{c}}$. Declines in low-latitude NPP in simulations K1-K6 are not fully offset by increasing NPP in the Southern Ocean, which is driven by regional increasing temperature, wind-driven overturning, and nutrient remineralisation (Kvale et al., 2015). K1 and K2 demonstrate a particularly strong increase in NPP in the Southern Ocean around $60^{\circ} \mathrm{S}$, for reasons discussed below. Along the Antarctic margin (around $80^{\circ} \mathrm{S}$ ), local freshening causes large local declines in NPP in simulations using weaker self-shading, though the region is not nutrient-limited in our model. The mechanism for the decline is a drop in seawater temperature in the second ocean depth layer, which disproportionately affects simulations that have deeper NPP. Simulations $\mathrm{K} 7$ and $\mathrm{K} 8$ are relatively less sensitive to increasing stratifica- 

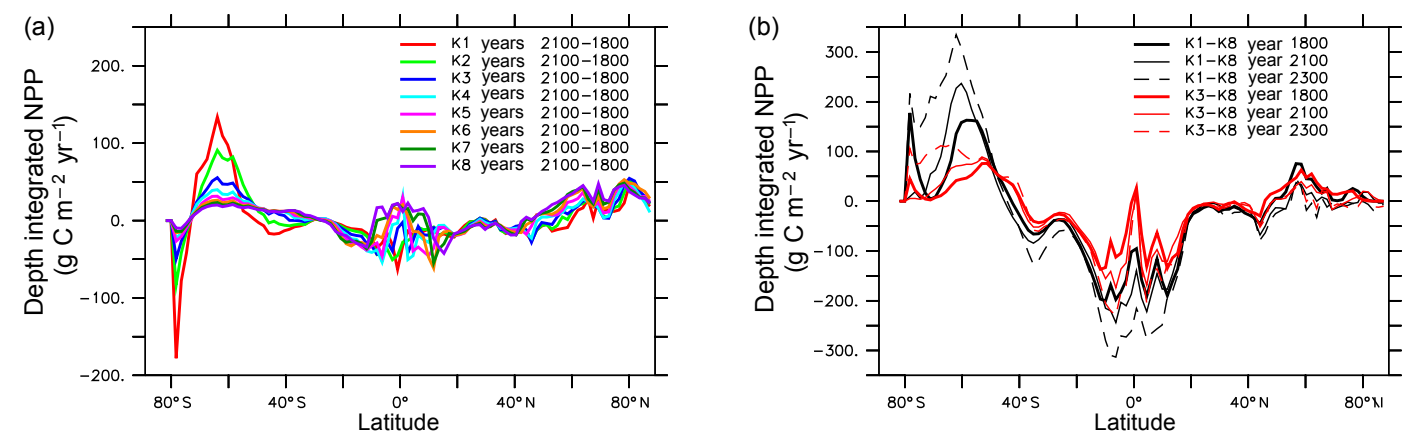

Figure 6. Change in annually and zonally averaged depth-integrated NPP between years 2100 and 1800 (a) and annually and zonally averaged depth-integrated NPP differences between K1 and K8 (black lines) and K3 and K8 (red lines) at three time slices (b).

tion (and associated nutrient limitation) because their high $k_{\mathrm{c}}$ values raise primary production higher in the water column, thereby raising surface nutrient concentrations and allowing the phytoplankton to be less reliant on resupply of nutrients from deeper waters. Pre-2100 global NPP increases in K8 are therefore attributable to increased biological rates due to warming. All simulations show an increase in NPP north of about 50 to $60^{\circ} \mathrm{N}$, which is driven by warming temperatures in all light attenuation tests.

After year 2100, physical limitation of nutrients becomes a less important driver of changes in global NPP than temperature-enhanced biological processes (Kvale et al., 2015). Increasing global NPP in lower $k_{\mathrm{c}}$ simulations is dominated by increasing NPP in the Southern Ocean, and in higher $k_{\mathrm{c}}$ simulations is a combination of increasing NPP in the Southern Ocean and at low latitudes. The drivers of change in NPP after year 2100 in the Southern Ocean are the same as those mentioned earlier, with alleviation of light limitation (Fig. 3) and warming seawater temperatures increasing production rates, to particular effect on low-value $k_{\mathrm{c}}$ simulations. The driver of change in NPP after year 2100 in the tropics is the increase in temperature-enhanced biological processes. Increasing divergence in zonal mean NPP between simulations is shown in Fig. 6 (right plot). At year 1800, Southern Ocean depth-integrated and zonally averaged NPP in $\mathrm{K} 1$ exceeds that in $\mathrm{K} 8$ by $180 \mathrm{~g} \mathrm{C} \mathrm{m}^{-3} \mathrm{yr}^{-1}$ at most. By year 2100, this difference has increased to $250 \mathrm{~g} \mathrm{C} \mathrm{m}^{-3} \mathrm{yr}^{-1}$, and by year 2300 it is over $300 \mathrm{~g} \mathrm{C} \mathrm{m}^{-3} \mathrm{yr}^{-1}$ (corresponding to more than $150 \%$ of $\mathrm{K} 1$ pre-industrial Southern Ocean zonal mean NPP). The pattern is similar but opposite at the low latitudes, where depth-integrated and zonally averaged NPP in $\mathrm{K} 8$ exceeds that in $\mathrm{K} 1$ by about $200 \mathrm{~g} \mathrm{C} \mathrm{m}^{-3} \mathrm{yr}^{-1}$ in year 1800 , around $250 \mathrm{~g} \mathrm{C} \mathrm{m}^{-3} \mathrm{yr}^{-1}$ in year 2100 , and more than $300 \mathrm{~g} \mathrm{C} \mathrm{m}^{-3} \mathrm{yr}^{-1}$ in year 2300. Divergence in depthintegrated and zonally averaged NPP for K3 and K8 follows the same pattern with smaller magnitudes $-\mathrm{K} 3$ exceeds $\mathrm{K} 8$ in the Southern Ocean by as much as $75 \mathrm{~g} \mathrm{C} \mathrm{m}^{-3} \mathrm{yr}^{-1}$ (year 1800) and $100 \mathrm{~g} \mathrm{C} \mathrm{m}^{-3} \mathrm{yr}^{-1}$ (year 2300, a difference of $60 \%$ of the highest pre-industrial K3 Southern Ocean zonal NPP value), and $\mathrm{K} 8$ exceeds $\mathrm{K} 3$ at the low latitudes by up to about
$130 \mathrm{~g} \mathrm{C} \mathrm{m}^{-3} \mathrm{yr}^{-1}$ (year 1800) and over $200 \mathrm{~g} \mathrm{C} \mathrm{m}^{-3} \mathrm{yr}^{-1}$ (year 2300). Throughout the simulations, Northern Hemisphere differences between $\mathrm{K} 1$ and $\mathrm{K} 8$ and $\mathrm{K} 3$ and $\mathrm{K} 8$ are relatively small, as the regional trends in responses to nutrient limitation are less cohesive than in the other regions.

The biogeochemical consequences of $k_{\mathrm{c}}$ parameter choice at years 1800 and 2300 are shown for major ocean basins in Fig. 7. Most biogeochemical quantities retain the preindustrial spread in global profiles with increasing $\mathrm{CO}_{2}$ forcing (for both $\mathrm{K} 1-\mathrm{K} 8$ and $\mathrm{K} 3-\mathrm{K} 8$ ), with changes on basin scale cancelling out in the global mean. This observation likely relates to the asymmetry in Southern Ocean/tropical trends in NPP K1-K8 differences noted in the previous paragraph (NPP rates in K1 exceed those of K8 in the Southern Ocean roughly equally to the amount NPP rates in K8 exceed those of $\mathrm{K} 1$ in the tropics). Basins reveal increasing changes with time. In particular, biogeochemical quantities in the deep Southern Ocean display increasing sensitivity to light attenuation parameter choice with time. At $5000 \mathrm{~m}$ in depth, by year 2300 the $\mathrm{K} 1-\mathrm{K} 8$ difference in average Southern Ocean alkalinity is $50 \mu \mathrm{mol} \mathrm{kg}^{-1}$ (compared to $25 \mu \mathrm{mol} \mathrm{kg}^{-1}$ at year 1800), while the difference in DIC has increased to $170 \mu \mathrm{mol} \mathrm{kg}{ }^{-1}\left(110 \mu \mathrm{mol} \mathrm{kg} \mathrm{kg}^{-1}\right.$ at year 1800). Alkalinity and DIC are higher in the K1 simulation because of higher NPP and stronger associated carbon export to the deep Southern Ocean compared to K8. Phosphate concentration differences at year 2300 and $5000 \mathrm{~m}$ in depth equal $0.8 \mathrm{mmol} \mathrm{m}^{-3}\left(0.5 \mathrm{mmol} \mathrm{m}^{-3}\right.$ at year 1800$)$, nitrate concentration differences exceed $10 \mathrm{mmol} \mathrm{m}^{-3}$ at year 2300 $\left(9 \mathrm{mmol} \mathrm{m}^{-3}\right.$ at year 1800), and oxygen concentration differences equal $180 \mathrm{mmol} \mathrm{m}^{-3}$ at year $2300\left(120 \mathrm{mmol} \mathrm{m}^{-3}\right.$ at year 1800).

All simulations experience a loss in oxygen due to warming and increasing remineralisation, but $\mathrm{K} 1$ and $\mathrm{K} 2$ additionally experience denitrification in the Southern Ocean (not shown) as a result of very high primary production in the region and already lower oxygen concentrations at pre-industrial equilibrium. This denitrification establishes a nutrient feedback with the low-latitude Pacific and Indian oceans that reduces Southern Ocean oxygen further (Fig. 8), 

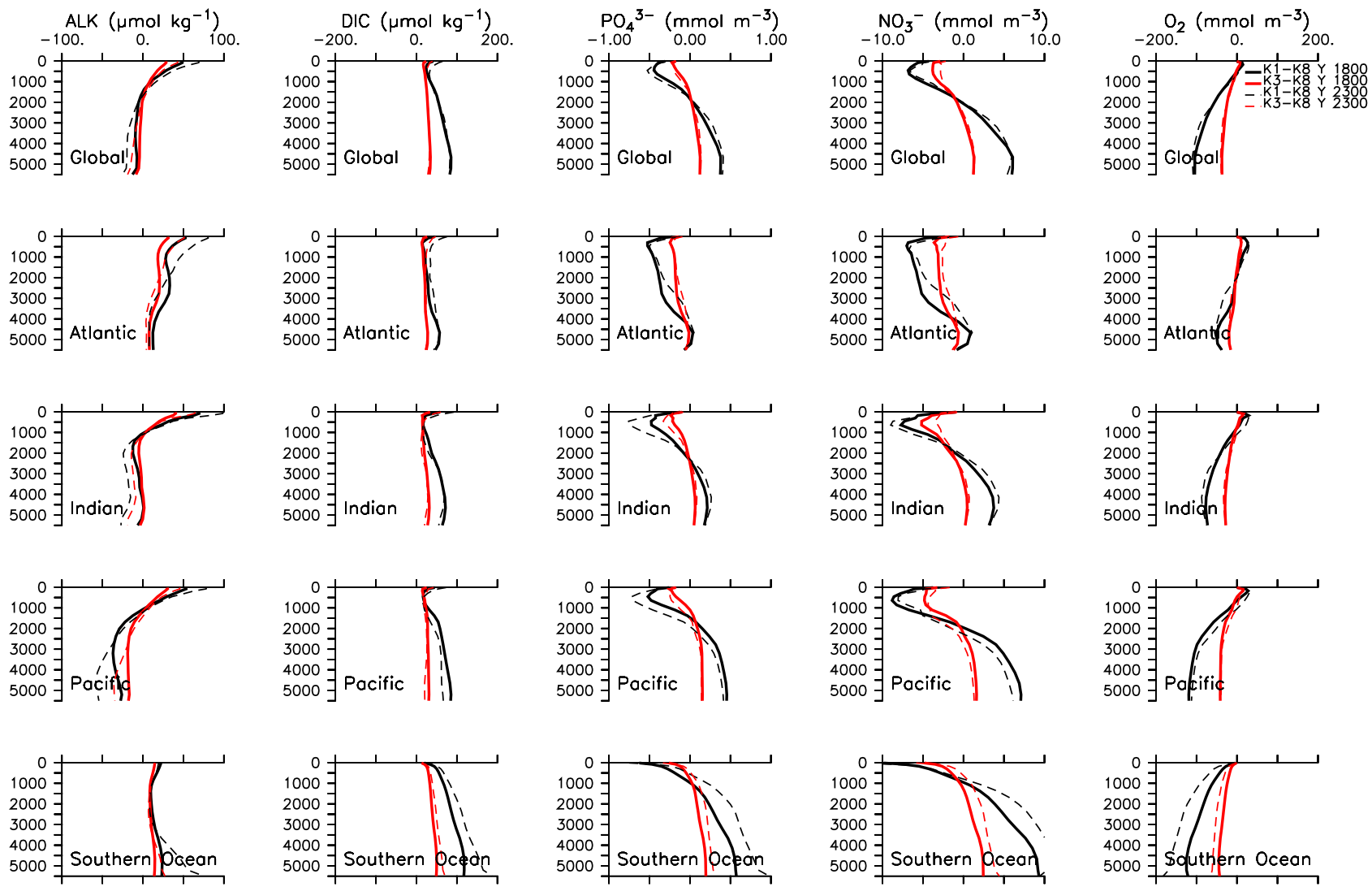

Figure 7. Annual mean biogeochemical tracer profile differences between $\mathrm{K} 1$ and $\mathrm{K} 8$ (black lines) and $\mathrm{K} 3$ and $\mathrm{K} 8$ (red lines), averaged by ocean basin for all simulations at years 1800 (solid lines) and 2300 (dashed lines).

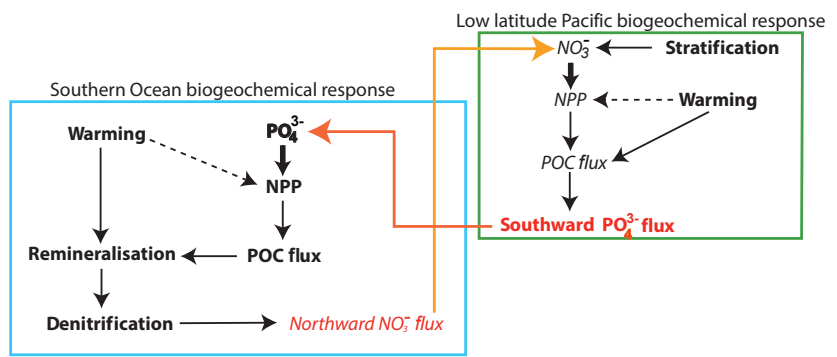

Figure 8. K1 and K2 feedback schematic in Southern Ocean and low-latitude Pacific nutrients. Increases with climate change are represented in bold font. Decreases with climate change are represented in italic font. Regular font indicates little or no change with climate forcing. Bold arrows indicate the dominant factor influencing change in NPP. Dashed arrows indicate the secondary factor influencing change in NPP. Nutrient feedback between regions is shown in coloured arrows.

thus producing a strong regional decline in oxygen despite K1 and K2 showing weaker global NPP trends than the other simulations. The feedback starts with increased stratification in the low-latitude Pacific and Indian oceans (to which low $k_{\mathrm{c}}$ simulations are particularly sensitive), which limits ni- trate availability for local primary production. As a result, more phosphate begins to advect into the Southern Ocean, where it fertilizes phytoplankton growth. The regional loss of phosphate in the western Pacific and Indian oceans in $\mathrm{K} 1$ and $\mathrm{K} 3$ can be seen in Fig. 3 as expanding phosphatelimited regimes. Warming seawater increases both primary production and remineralisation rates. Phytoplankton in K1 and $\mathrm{K} 2$ are only weakly inhibited by self-shading and take full advantage of warmer temperatures and imported nutrients, and the resulting large increases in primary production lead to the consumption of enough oxygen that denitrification is established in the Southern Ocean. Denitrification reduces the flow of nitrate in intermediate water back into the lowlatitude Pacific and Indian basins, which become even more nitrate-limited.

Excluding the $\mathrm{K} 1$ and $\mathrm{K} 2$ simulations in which Southern Ocean denitrification occurs, differences between K3 and K8 biogeochemical quantities change less over time, though the spread in Southern Ocean intermediate and deep nitrate concentrations increases by about $50 \%$ (Fig. 7). 


\section{Discussion}

The pre-industrial equilibrium simulations demonstrate a sensitivity in zonally averaged NPP, and global and basin profiles of biogeochemistry to choice of $k_{\mathrm{c}}$ value for the range tested. Simulation spread is greatest in the Southern Ocean and tropics. Simulation differences arise from a complex interplay of factors. Higher light attenuation values have a stronger self-shading effect on phytoplankton, which acts to increase NPP in stratified, nutrient-limited regions (the low latitudes in our model). This is because strong selfshading raises the depth profile of primary production into the warmest surface ocean layer by reducing the amount of light available in lower layers. Biological processes have a temperature dependency in the UVic ESCM, so reduced nutrient utilization in deeper layers increases nutrient availability at the surface, increasing surface net primary production. This finding somewhat agrees with Kim et al. (2015), who found a decoupling between nutrient concentrations and biomass when light attenuation of CDOM was accounted for in their ESM. Including light attenuation of CDOM (therefore raising total model light attenuation) increased surface nutrient concentrations in their model through a similar mechanism (shoaling of the biomass and production profiles); however, they found that CDOM light attenuation decreased depth-integrated biomass and attributed the increasing surface nutrients to less total production. Our model demonstrates an increase in depth-integrated NPP with increasing light attenuation. The Kim et al. (2015) model allowed biological light attenuation to reduce shortwave heating of the water column, while our model does not account for this. Including a reduction of near-surface temperatures with strong self-shading might reduce the increase we find in NPP with higher values of $k_{\mathrm{c}}$, though Manizza et al. (2005) found that inclusion of a shortwave feedback to NPP can also enhance spring sea surface temperatures and reduce sea ice.

Our model is also nutrient-limited in the tropical eastern Pacific upwelling zone, but this region is also well mixed (near-surface shoaling of the nutrient profile is weaker and the near-surface temperature gradient is lower), so greater light inhibition of deeper photosynthesis results in less NPP with higher $k_{\mathrm{c}}$ values. In the Southern Ocean, higher NPP is the result of lower light attenuation values, which allow phytoplankton in the light-limited regions to produce deeper in the water column. In simulations with lower light attenuation values, NPP also increases in the northern parts of the Southern Ocean, which are nutrient-limited in our model. This may be a response to nutrient advection from locally increased near-surface remineralisation arising from higher NPP in the light-limited regions, and highlights the important point that light attenuation parameter choice can potentially have surprising effects on nutrient transport by changing the depth of primary production. Keller et al. (2016) found a similar effect at this latitude by suppressing primary production around Antarctica, which caused a northward advection of nutrients, raising local NPP. In this particular region, higher vertical resolution might reduce the overall NPP response of the Southern Ocean to decreasing a light attenuation parameter by reducing advected regenerated nutrients and reducing preformed nutrients made available for primary production by reduced self-shading. At the stratified low latitudes, higher vertical resolution might reduce the nutrient shoaling effect of strong self-shading.

Though iron availability is accounted for in the form of a seasonally variable mask, in our model iron is not a limiting nutrient on an annually averaged basis. This is in contrast to evidence of iron limitation in the Southern Ocean, North Atlantic, and eastern boundary currents and upwelling systems (see the recent review by Tagliabue et al., 2017). More iron limitation of phytoplankton growth in the UVic ESCM might damp the NPP response we show for lower light attenuation simulations in the Southern Ocean and eastern equatorial Pacific. More iron limitation might also mitigate differences in the efficiency of the global biological pump between high- and low-value light attenuation parameter simulations. Higher NPP at the high latitudes in low-value light attenuation parameter simulations results in more efficient export and storage of nutrients in the deep ocean, particularly the abyssal North Pacific (also found by DeVries et al., 2012). Model phosphate is conserved in our simulations; thus, larger deep ocean inventories result in lower concentrations in downstream surface and intermediate waters (in qualitative agreement with Kwon and Primeau, 2006; Kriest et al., 2012). The effect of enhanced deep nutrient sequestration is most apparent in Atlantic phosphate and nitrate profiles, where concentrations are lower for lower $k_{\mathrm{c}}$ simulations and NPP is not very much higher at the surface, in spite of being a seasonally well-mixed region. If iron were more limiting in the Southern Ocean deep water formation regions, fewer nutrients would be sequestered in the deep Pacific and more would be available to the North Atlantic, raising regional primary production and export (assuming no iron limitation also existed in the North Atlantic). More iron limitation at the low latitudes might furthermore damp the NPP response of higher $k_{\mathrm{c}}$ simulations in the thermally stratified tropics, thus increasing nutrient transport poleward and increasing high-latitude NPP.

Parameter estimation and the quantification of biogeochemical model uncertainty is a major field of research (see the review by Schartau et al., 2017). Our study demonstrates the importance of considering transient model behaviour in both parameter estimation and estimates of uncertainties for biogeochemistry in OGCMs and ESMs. Differences in the relative importance of regional biological pumps to global NPP between high- and low-light attenuation simulations have a strong effect on how the model responds to climate change. Using a lower $k_{\mathrm{c}}$ value emphasizes the Southern Ocean response, where physical drivers of warming temperatures and increasing light availability enhance NPP, while using higher $k_{\mathrm{c}}$ values places increasing importance on the 
tropical drivers of warming and stratification. Thus, simulation spread increases in our transient simulations, and $k_{\mathrm{c}}$ parameter choice can determine the sign as well as the magnitude of the global NPP response, particularly in the near term (to year 2100), when physical changes are the dominant model drivers of NPP. Simulations K6 to K8 perform roughly equivalently with respect to biogeochemical observations in the pre-industrial equilibrium, and yet global NPP differences by 2100 are around $2 \mathrm{Pg} \mathrm{Cyr}^{-1}$, with $\mathrm{K} 8$ showing an increase and $\mathrm{K} 6$ showing a decrease with respect to year 1800 NPP. A recent review of the drivers of change in global NPP in a suite of OGCMs and ESMs to which climate forcing was applied found the low latitudes contained the largest spread in model response, with global trends comprising a balance between increasing metabolic rates and increasing stratification (Laufkötter et al., 2015). Our results suggest differences between this balance across models might be partly related to differences in the treatment of phytoplankton light attenuation.

Climate change furthermore compounds regional differences in biological pumps according to light attenuation parameter choice, as nutrient export from the tropics to the Southern Ocean increases in low- $k_{\mathrm{c}}$ value simulations due to the disproportionate sensitivity of low- $k_{\mathrm{c}}$ value simulations to low-latitude stratification. Low-latitude nutrient recycling is strongly enhanced in high- $k_{\mathrm{c}}$ value simulations due to surface warming and shallow NPP, reducing the availability of regenerated nutrients for export to the high latitudes and damping increasing NPP in the Southern Ocean. Where NPP responds to climate change has implications for long-term carbon sequestration, which can be seen as a $180 \mu \mathrm{mol} \mathrm{kg}-1$ deep Southern Ocean DIC surplus and rising DIC concentrations in the near-surface Atlantic in the K1 simulation when compared to K8 by year 2300. Furthermore, ocean oxygen shows particular sensitivity to light attenuation parameter choice when forcing the model with future projections. That oxygen is sensitive to model treatment of NPP (e.g. Kriest et al., 2012), and that Southern Ocean biological processes can affect global nutrient, carbon, and oxygen distributions (e.g. Kwon and Primeau, 2006; DeVries et al., 2012; Kriest et al., 2012; Keller et al., 2016), are not new findings, but, as far as we know, our study is the first to demonstrate the potential for denitrification in the Southern Ocean. The nutrient exchange feedback that is established in the two lowest $k_{\mathrm{c}}$ value simulations ( $\mathrm{K} 1$ and $\mathrm{K} 2$ ) substantially reduces Southern Ocean oxygen concentrations. Our model is highly idealized, but it is worth noting that the nutrient exchange feedback occurs because (1) it highlights the potential for strong biogeochemical teleconnection between the Southern Ocean and the low-latitude Pacific in the real world, and (2) light attenuation characteristics of dominant phytoplankton (Katz et al., 2004) and ocean oxygen content (Lenton et al., 2014) and rates of change (e.g. Paleocene Eocene Thermal Maximum; Norris et al., 2013) have changed over geologic timescales. A recent model study by Meyer et al. (2016) ex- plored the sensitivity of oxygen to e-folding depth of remineralisation and total phosphate inventory and hypothesized an increase in remineralisation depth has occurred over the Phanerozoic alongside a stabilisation of the ocean oxygen inventory. Our tests demonstrate another potential mechanism for the increase in ocean oxygen inventory in equilibrated conditions as well as for a stabilisation of oxygen under rapid climate change - an evolved increase in light attenuation by dominant phytoplankton, which in our model increases the ocean oxygen inventory and mitigates total oxygen change with climate forcing.

It is possible that primary production in our model demonstrates similarly increasing sensitivity to other phytoplankton parameters with climate change, and that the sensitivity of NPP to $k_{\mathrm{c}}$ may be damped or magnified by the choice of other parameter values (e.g. the initial value of the photosynthesisirradiance curve). Exploring the uncertainty associated with multiple parameter manipulations is costly and better left to offline approaches that can objectively and systematically assess the solution space (see the review by Schartau et al., 2017), though as far as we know, offline methods for threedimensional models are currently restricted to steady-state analysis. It is also possible that including a fully resolved radiative transfer model and explicit IOPs for multiple phytoplankton types could damp the Southern Ocean response we find in $\mathrm{K} 1$ and $\mathrm{K} 2$ and the low-latitude response we find in the higher light attenuation simulations (Gregg and Rousseaux, 2016). Lastly, the impact of phytoplankton shading on water column heating is not considered here. This is a potentially significant omission with respect to the climate change response of model physics as global net primary production increases strongly in all of our simulations but never contributes to regional cooling, in contrast to the Manizza et al. (2005) finding that light attenuation by biomass can amplify the seasonal cycle of temperature, mixed layer depth, and ice cover by about $10 \%$ under pre-industrial conditions. From a global perspective, increasing shortwave penetration along the Equator can warm regions to the south (Gnanadesikan and Anderson, 2009), which might damp southward nutrient transport in our low-light attenuation simulations by increasing local export production. However, increasing shortwave penetration in the Southern Ocean can enhance mode water formation from subtropical water (Gnanadesikan and Anderson, 2009), which might enhance the positive nutrient feedback we demonstrate in low- $k_{\mathrm{c}}$ simulations. Regardless, the UVic ESCM is fairly typical with respect to other ESMs with regard to the treatment of the underwater light field; therefore, our sensitivity study is useful for assessing uncertainty in models of similar structure.

\section{Conclusions}

The highly simplistic parameterisation of underwater light availability used in the UVic ESCM to calculate primary 
production and associated chemistry (alkalinity, DIC, nitrate, phosphate, and oxygen) is sensitive to a range of light attenuation parameter values constrained by data. This applies to both pre-industrial equilibrium and future projections. This sensitivity can grow with changing background climate as complex biogeochemical feedbacks develop, with primary production and ocean oxygen being especially susceptible to parameter choice. Our study highlights the need to assess biogeochemical models under transient as well as equilibrium conditions. In addition, the biogeochemical feedback we describe in two of our transient simulations also serves as a reminder that even seemingly small events, like the emergence of shell-secreting phytoplankton, could have potentially large biogeochemical consequences just by altering the underwater light field.

Code availability. Model data and figure scripts are available from https://thredds.geomar.de/thredds/catalog/open_access/kvale_ meissner_2017_bg/catalog.html (GEOMAR, 2017). Model code is available from the authors upon request.

Author contributions. KFK designed and implemented the experiment, and wrote the paper with comments by KJM. KFK and KJM interpreted the model results.

Competing interests. The authors declare that they have no conflict of interest.

Acknowledgements. Computing resources were provided by Kiel University.

The article processing charges for this open-access publication were covered by a Research

Centre of the Helmholtz Association.

Edited by: Victor Brovkin

Reviewed by: two anonymous referees

\section{References}

Battle, M., Bender, M., Sowers, T., Tans, P., Butler, J., Elkins, J., Ellis, J., Conway, T., Zhang, N., Lang, P., and Clarke, A.: Atmospheric gas concentrations over the past century measured in air from firn at the South Pole, Nature, 383, 231-235, https://doi.org/10.1038/383231a0, 1996.

Bracher, A. and Tilzer, M.: Underwater light field and phytoplankton absorbance in different surface water masses of the Atlantic sector of the Southern Ocean, Polar Biology, 24, 687-696, https://doi.org/10.1007/s003000100269, 2001.

DeVries, T., Primeau, F., and Deutsch, C.: The sequestration efficiency of the biological pump, Geophys. Res. Lett., 39, 113601, https://doi.org/10.1029/2012GL051963, 2012.
Dutkiewicz, S., Hickman, A. E., Jahn, O., Gregg, W. W., Mouw, C. B., and Follows, M. J.: Capturing optically important constituents and properties in a marine biogeochemical and ecosystem model, Biogeosciences, 12, 4447-4481, https://doi.org/10.5194/bg-12-4447-2015, 2015.

Eby, M., Zickfeld, K., Montenegro, A., Archer, D., Meissner, K. J., and Weaver, A. J.: Lifetime of anthropogenic climate change: Millennial time scales of potential $\mathrm{CO}_{2}$ and surface temperature perturbations, J. Climate, 22, 2501-2511, https://doi.org/10.1175/2008JCLI2554.1, 2009.

Etheridge, D., Steele, L., Langenfelds, R., Francey, R., Barnola, J., and Morgan, V.: Natural and anthropogenic changes in atmospheric $\mathrm{CO}_{2}$ over the last 1000 years from air in Antarctic ice and firn, J. Geophys. Res.-Atmos., 101, 4115-4128, https://doi.org/10.1029/95JD03410, 1996.

Etheridge, D., Steele, L., Francey, R., and Langenfelds, R.: Atmospheric methane between $1000 \mathrm{AD}$ and present: Evidence of anthropogenic emissions and climatic variability, J. Geophys. Res.Atmos., 103, 15979-15993, https://doi.org/10.1029/98JD00923, 1998.

Evans, G. T. and Parslow, J. S.: A model of annual plankton cycles, Biological Oceanography, 3, 327-347, https://doi.org/10.1016/0198-0254(85)92902-4, 1985.

Falkowski, P. and Woodhead, A. (Eds.): Primary productivity and biogeochemical cycles in the sea, Proceedings of the conference on primary productivity and biogeochemical cycles in the sea, Brookhaven National Laboratory, Plenum Press, 1992.

Falkowski, P. G., Gan, R., and Wyman, K.: Growth-irradiance relationships in phytoplankton, Limnol. Oceanogr., 30, 311-321, 1985.

Fasham, M. J. R., Ducklow, H. W., and McKelvie, S. M.: A nitrogen-based model of plankton dynamics in the oceanic mixed layer, J. Marine Res., 48, 591-639, https://doi.org/10.1357/002224090784984678, 1990.

Ferretti, D., Miller, J., White, J., Etheridge, D., Lassey, K., Lowe, D., Meure, C., Dreier, M., Trudinger, C., van Ommen, T., and Langenfelds, R.: Unexpected changes to the global methane budget over the past 2000 years, Science, 309, 1714-1717, https://doi.org/10.1126/science.1115193, 2005.

Flückiger, J., Dällenbach, A., Blunier, T., Stauffer, B., Stocker, T. F., Raynaud, D., and Barnola, J.-M.: Variations in atmospheric N2O concentration during abrupt climatic changes, Science, 285, 227 230, https://doi.org/10.1126/science.285.5425.227, 1999.

Flückiger, J., Blunier, T., Stauffer, B., Chappellaz, J., Spahni, R., Kawamura, K., Schwander, J., Stocker, T. F., and Dahl-Jensen, D.: $\mathrm{N}_{2} \mathrm{O}$ and $\mathrm{CH}_{4}$ variations during the last glacial epoch: Insight into global processes, Global Biogeochem. Cy., 18, GB1020, https://doi.org/10.1029/2003GB002122, 2004.

Fujii, M., Boss, E., and Chai, F.: The value of adding optics to ecosystem models: a case study, Biogeosciences, 4, 817-835, https://doi.org/10.5194/bg-4-817-2007, 2007.

Garcia, H., Locarnini, R. A., Boyer, T. P., Antonov, J., Baranova, O., Zweng, M. M., and Johnson, D.: World Ocean Atlas 2009, Volume 3: Dissolved Oxygen, Apparent Oxygen Utilization, and Oxygen Saturation, Tech. rep., NOAA Atlas NESDIS 70, U.S. Government Printing Office, Washington, D.C., 2010a.

Garcia, H., Locarnini, R. A., Boyer, T. P., Antonov, J., Zweng, M. M., Baranova, O., and Johnson, D.: World Ocean Atlas 2009, Volume 4: Nutrients (phosphate, nitrate, silicate), Tech. rep., 
NOAA Atlas NESDIS 71, U.S. Government Printing Office, Washington, D.C., $2010 \mathrm{~b}$.

GEOMAR: Catalog of Gridded Data, available at: https: //thredds.geomar.de/thredds/catalog/open_access/kvale_ meissner_2017_bg/catalog.html, last access: October 2017.

Gnanadesikan, A. and Anderson, W. G.: Ocean water clarity and the ocean general circulation in a coupled climate model, J. Phys. Oceanogr., 39, 314-332, https://doi.org/10.1175/2008JPO3935.1, 2009.

Gregg, W. W. and Rousseaux, C. S.: Directional and spectral irradiance in ocean models: Effects on simulated global phytoplankton, nutrients, and primary production directional and spectral irradiance in ocean models, Front. Mar. Sci, 3, 240, https://doi.org/10.3389/fmars.2016.00240, 2016.

Hurtt, G. C., Chini, L. P., Frolking, S., Betts, R. A., Feddema, J., Fischer, G., Fisk, J. P., Hibbard, K., Houghton, R. A., Janetos, A., Jones, C. D., Kindermann, G., Kinoshita, T., Klein Goldewijk, K., Riahi, K., Shevliakova, E., Smith, S., Stehfest, E., Thomson, A., Thornton, P., van Vuuren, D. P., and Wang, Y. P.: Harmonization of land-use scenarios for the period 1500-2100: 600 years of global gridded annual land-use transitions, wood harvest, and resulting secondary lands, Climatic Change, 109, 117, https://doi.org/10.1007/s10584-011-0153-2, 2011.

Kalnay, E., Kanamitsu, M., Kistler, R., Collins, W., Deaven, D., Gandin, L., Iredell, M., Saha, S., White, G., Woollen, J., Zhu, Y., Chelliah, M., Ebisuzaki, W., Higgins, W., Janowiak, J., Mo, K., Ropelewski, C., Wang, J., Leetmaa, A., Reynolds, R., Jenne, R., and Joseph, D.: The NCEP/NCAR 40-year reanalysis project, B. Am. Meteorol. Soc., 77, 437-471, https://doi.org/10.1175/15200477(1996)077<0437:TNYRP>2.0.CO;2, 1996.

Katz, M. E., Finkel, Z. V., Grzebyk, D., Knoll, A. H., Paul, G., and Falkowski, P. G.: Evolutionary trajectories and biogeochemical impacts of marine eukaryotic phytoplankton, Annual Review of Ecology, Evolution and Systematics, 35, 523556, https://doi.org/10.1146/annurev.ecolsys.35.112202.130137, 2004

Keller, D. P., Oschlies, A., and Eby, M.: A new marine ecosystem model for the University of Victoria Earth System Climate Model, Geosci. Model Dev., 5, 1195-1220, https://doi.org/10.5194/gmd-5-1195-2012, 2012.

Keller, D. P., Kriest, I., Koeve, W., and Oschlies, A.: Southern Ocean biological impacts on global ocean oxygen, Geophys. Res. Lett., 43, 6469-6477, https://doi.org/10.1002/2016GL069630, 2016

Kettle, H. and Merchant, C. J.: Modeling ocean primary production: Sensitivity to spectral resolution of attenuation and absorption of light, Prog. Oceanogr., 78, 135-146, https://doi.org/10.1016/j.pocean.2008.04.002, 2008.

Key, R., Kozyr, A., Sabine, C., Lee, K., Wanninkhof, R., Bullister, J., Feely, R., Millero, F., and Mordy, C.: A global ocean carbon climatology: Results from GLODAP, Global Biogeochem. Cy., 18, GB4031, https://doi.org/10.1029/2004GB002247, 2004.

Kim, G. E., Pradal, M.-A., and Gnanadesikan, A.: Quantifying the biological impact of surface ocean light attenuation by colored detrital matter in an ESM using a new optical parameterization, Biogeosciences, 12, 5119-5132, https://doi.org/10.5194/bg-125119-2015, 2015.

Kirk, J. T. O.: A theoretical analysis of the contribution of algal cells to the attenuation of light within natural waters I: General treat- ment of suspensions of pigmented cells, New Phytol., 75, 11-20, https://doi.org/10.1111/j.1469-8137.1975.tb01366.x, 1975.

Kirk, J. T. O.: Light and Photosynthesis in Aquatic Ecosystems, Cambridge University Press, 1983.

Kriest, I., Oschlies, A., and Khatiwala, S.: Sensitivity analysis of simple global marine biogeochemical models, Global Biogeochem. Cy., 26, gB2029, https://doi.org/10.1029/2011GB004072, 2012.

Kvale, K. F., Meissner, K. J., and Keller, D. P.: Potential increasing dominance of heterotrophy in the global ocean, Environ. Res. Lett., 10, 074009, https://doi.org/10.1088/17489326/10/7/074009, 2015.

Kwon, E. Y. and Primeau, F.: Optimization and sensitivity study of a biogeochemistry ocean model using an implicit solver and in situ phosphate data, Global Biogeochemical Cycles, 20, gB4009, https://doi.org/10.1029/2005GB002631, 2006.

Kwon, E. Y., Primeau, F., and Sarmiento, J. L.: The impact of remineralization depth on the air-sea carbon balance, Nature Geosci., 2, 630-635, https://doi.org/10.1038/ngeo612, 2009.

Laufkötter, C., Vogt, M., Gruber, N., Aita-Noguchi, M., Aumont, O., Bopp, L., Buitenhuis, E., Doney, S. C., Dunne, J., Hashioka, T., Hauck, J., Hirata, T., John, J., Le Quéré, C., Lima, I. D., Nakano, H., Seferian, R., Totterdell, I., Vichi, M., and Völker, C.: Drivers and uncertainties of future global marine primary production in marine ecosystem models, Biogeosciences, 12, 69556984, https://doi.org/10.5194/bg-12-6955-2015, 2015.

Lenton, T. M., Boyle, R. A., Poulton, S. W., Shields-Zhou, G. A., and Butterfield, N. J.: Co-evolution of eukaryotes and ocean oxygenation in the Neoproterozoic era, Nature Geosci., 7, 257-265, 2014.

Lorenzen, C.: Extinction of light in ocean by phytoplankton, Journal du Conseil, 34, 262-267, 1972.

Machida, T., Nakazawa, T., Fujii, Y., Aoki, S., and Watanabe, O.: Increase in the atmospheric nitrous-oxide concentration during the last 250 years, Geophys. Res. Lett., 22, 2921-2924, https://doi.org/10.1029/95GL02822, 1995.

Manizza, M., Le Quere, C., Watson, A., and Buitenhuis, E.: Biooptical feedbacks among phytoplankton, upper ocean physics and sea-ice in a global model, Geophys. Res. Lett., 32, L05603, https://doi.org/10.1029/2004GL020778, 2005.

Meinshausen, M., Smith, S. J., Calvin, K., Daniel, J. S., Kainuma, M. L. T., Lamarque, J.-F., Matsumoto, K., Montzka, S. A., Raper, S. C. B., Riahi, K., Thomson, A., Velders, G. J. M., and van Vuuren, D. P. P.: The RCP greenhouse gas concentrations and their extensions from 1765 to 2300, Climatic Change, 109, 213-241, https://doi.org/10.1007/s10584-011-0156-z, 2011.

Meissner, K. J., McNeil, B. I., Eby, M., and Wiebe, E. C.: The importance of the terrestrial weathering feedback for multimillennial coral reef habitat recovery, Global Biogeochem. Cy., 26, GB3017, https://doi.org/10.1029/2011GB004098, 2012.

Meure, M. C., Etheridge, D., Trudinger, C., Steele, P., Langenfelds, R., van Ommen, T., Smith, A., and Elkins, J.: Law Dome $\mathrm{CO}_{2}, \mathrm{CH} 4$ and $\mathrm{N} 2 \mathrm{O}$ ice core records extended to 2000 years BP, Geophys. Res. Lett., 33, L14810, https://doi.org/10.1029/2006GL026152, 2006.

Meyer, K. M., Ridgwell, A., and Payne, J. L.: The influence of the biological pump on ocean chemistry: Implications for longterm trends in marine redox chemistry, the global carbon cy- 
cle, and marine animal ecosystems, Geobiology, 14, 207-219, https://doi.org/10.1111/gbi.12176, 2016.

Norris, R. D., Turner, S. K., Hull, P. M., and Ridgwell, A.: Marine Ecosystem Responses to Cenozoic Global Change, Science, 341, 492-498, https://doi.org/10.1126/science.1240543, 2013.

Riahi, K., Gruebler, A., and Nakicenovic, N.: Scenarios of long-term socio-economic and environmental development under climate stabilization, Technological Forecasting and Social Change, 74, 887-935, https://doi.org/10.1016/j.techfore.2006.05.026, 2007.

Sathyendranath, S. and Platt, T.: Spectral effects in bio-optical control on the ocean system, Oceanologia, 49, 5-39, 2007.

Schartau, M., Wallhead, P., Hemmings, J., Löptien, U., Kriest, I., Krishna, S., Ward, B. A., Slawig, T., and Oschlies, A.: Reviews and syntheses: parameter identification in marine planktonic ecosystem modelling, Biogeosciences, 14, 1647-1701, https://doi.org/10.5194/bg-14-1647-2017, 2017.

Schmittner, A., Oschlies, A., Giraud, X., Eby, M., and Simmons, H.: A global model of the marine ecosystem for long-term simulations: Sensitivity to ocean mixing, buoyancy forcing, particle sinking, and dissolved organic matter cycling, Global Biogeochem. Cy., 19, GB3004, https://doi.org/10.1029/2004GB002283, 2005.

Schmittner, A., Oschlies, A., Matthews, H. D., and Galbraith, E. D.: Future changes in climate, ocean circulation, ecosystems, and biogeochemical cycling simulated for a business-as-usual $\mathrm{CO}_{2}$ emission scenario until year $4000 \mathrm{AD}$, Global Biogeochem. Cy., 22, GB1013, https://doi.org/10.1029/2007GB002953, 2008.
Siegel, D., Maritorena, S., Nelson, N., and Behrenfeld, M.: Independence and interdependencies among global ocean color properties: Reassessing the bio-optical assumption, J. Geophys. Res.Oceans, 110, C07011, https://doi.org/10.1029/2004JC002527, 2005.

Stramski, D., Bricaud, A., and Morel, A.: Modeling the inherent optical properties of the ocean based on the detailed composition of the planktonic community, Appl. Opt., 40, 2929-2945, https://doi.org/10.1364/AO.40.002929, 2001.

Tagliabue, A., Bowie, A. R., Boyd, P. W., Buck, K. N., Johnson, K. S., and Saito, M. A.: The integral role of iron in ocean biogeochemistry, Nature, 543, 51-59, https://doi.org/10.1038/nature21058, 2017.

Wang, X. J., Le Borgne, R., Murtugudde, R., Busalacchi, A. J., and Behrenfeld, M.: Spatial and temporal variations in dissolved and particulate organic nitrogen in the equatorial Pacific: biological and physical influences, Biogeosciences, 5, 1705-1721, https://doi.org/10.5194/bg-5-1705-2008, 2008.

Weaver, A., Eby, M., Wiebe, E., Bitz, C., Duffy, P., Ewen, T., Fanning, A., Holland, M., MacFadyen, A., Matthews, H., Meissner, K., Saenko, O., Schmittner, A., Wang, H., and Yoshimori, M.: The UVic Earth System Climate Model: Model description, climatology, and applications to past, present and future climates, Atmos.-Ocean, 39, 361-428, https://doi.org/10.1080/07055900.2001.9649686, 2001. 